\title{
DÜBLIN
}

Technological University Dublin

ARROW@TU Dublin

\section{Sol-Gel Silica Coated Optical Fiber Sensor for Ammonia Gas Detection}

\author{
Dejun Liu \\ Technological University Dublin \\ Arun Mallik \\ Technological University Dublin, arun.mallik@tudublin.ie \\ Wei Han \\ Technological University Dublin, wei.han@tudublin.ie
}

See next page for additional authors

Follow this and additional works at: https://arrow.tudublin.ie/radcon

Part of the Electrical and Electronics Commons, and the Electromagnetics and Photonics Commons

\section{Recommended Citation}

Liu, D., Mallik, A. \& Farrell, G. (2016). Sol-gel silica coated optical fiber sensor for ammonia gas detection. 15th International Conference on Optical Communications and Networks. 2016. doi:10.1109/ ICOCN.2016.7875756

This Conference Paper is brought to you for free and open access by the Radiation and Environmental Science Centre at ARROW@TU Dublin. It has been accepted for inclusion in Conference papers by an authorized administrator of ARROW@TU Dublin. For more information, please contact arrow.admin@tudublin.ie, aisling.coyne@tudublin.ie,gerard.connolly@tudublin.ie.

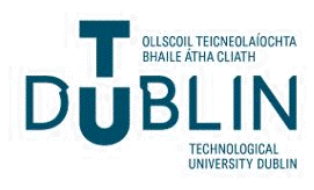


Authors

Dejun Liu, Arun Mallik, Wei Han, and Qiang wu

This conference paper is available at ARROW@TU Dublin: https://arrow.tudublin.ie/radcon/9 


\section{Sol-gel silica coated optical fiber sensor for ammonia gas detection}

Conference Paper · September 2016

DOI: $10.1109 /$ ICOCN.2016.7875756

CITATIONS

0

10 authors, including:

\section{Dejun Liu}

Dublin Institute of Technology

19 PUBLICATIONS 219 CITATIONS

SEE PROFILE

Yuliya Semenova

Dublin Institute of Technology

259 PUBLICATIONS $\quad 1,969$ CITATIONS

SEE PROFILE
Jin-Hui Yuan

Beijing University of Posts and Telecommuni... 210 PUBLICATIONS 462 CITATIONS

SEE PROFILE

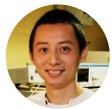

Qiang Wu

Northumbria University

213 PUBLICATIONS 1,343 CITATIONS

SEE PROFILE

Some of the authors of this publication are also working on these related projects:

Project Whispering Gallery Mode Fiber Resonators View project

nonlinear optics View project 


\title{
Sol-gel Silica Coated Optical Fiber Sensor for Ammonia Gas Detection
}

\author{
Dejun Liu ${ }^{1}$, Arun Kumar Mallik', Wei Han ${ }^{1}$, Fangfang Wei ${ }^{1}$, Lei Sun ${ }^{3}$, Jinhui Yuan ${ }^{3}$, Chongxiu Yu ${ }^{3}$, \\ Gerald Farrell', Yuliya Semenova ${ }^{1}$ and Qiang $W u^{2,1,3 *}$
}

${ }^{1}$ Photonics Research Centre, Dublin Institute of Technology, Kevin Street, Dublin 8, Ireland

${ }^{2}$ Department of Physics and Electrical Engineering, Northumbria University, Newcastle Upon Tyne, NE1 8ST, United Kingdom

${ }^{3}$ State Key Laboratory of Information Photonics and Optical Communications, Beijing University of Posts and Telecommunications, Beijing 100876, China

* qiang.wu@northumbria.ac.uk

\begin{abstract}
A high sensitivity ammonia gas sensor based on a tapered small core single-mode fiber (SCSMF) structure for measurement of ammonia gas concentration is reported. The proposed tapered SCSMF fiber structure has a waist diameter of $13.5 \mu \mathrm{m}$ and it is fabricated using a customized microheater brushing technique. The silica based material prepared by sol-gel method is used as a coating applied to the surface of tapered fiber structures. Experimental results show that sensor is very sensitive to ammonia. The best measurement resolution of the ammonia concentration is estimated to be 16 ppb for gas concentrations of $0.5 \mathrm{ppm}$ to $2.5 \mathrm{ppm}$ while the response and recovery times are less than 5 and 10 minutes respectively.
\end{abstract}

Keywords: Ammonia sensor, Optical fiber sensor, Silica, Small core single mode fiber

\section{INTRODUCTION}

Ammonia is widely used in various industrial processes and agricultural activities. Due to the fact that an excess of ammonia may cause air pollution and it also may have toxic effects on the health of both plants and human beings, it is essential to accurately monitor its concentration in the air [1-2]. During the past decade, a number of ammonia sensors based on different operating principles were proposed, such as electro-chemical sensors [3], metal oxide semiconductor sensors [4], ratiometric fluorescence sensors [5]. Recently, the development of fiber optic sensors for the detection of ammonia has increased rapidly [6-8] due to the significant advantages of optical fiber sensors such as a very compact size, immunity to electromagnetic interference, remote sensing capabilities, and most importantly, their ability to operate at room temperature.

Ammonia sensors based on optical fibers usually require some additional ammonia sensitive materials to be coated on the fiber surface. Physical or chemical reactions occurring when such sensitive materials come in contact with ammonia result in the change of optical properties of the sensor surface. One such physical/chemical reaction at the silica surface is adsorption which is well known and extensively investigated [9-10]. The adsorption will result in a refractive index (RI) change in the silica coating which in turn leads to the spectral shift of the transmission response of the fiber sensor. Thus ammonia concentration can be determined by detecting the variations of the sensor's spectral response assuming a suitable calibration has taken place. To the best of our knowledge there are no reports to date on the use of silica coating as the sensitive coating material for ammonia detection in fiber optic sensors. In our previous report, we have proposed a very high sensitivity RI sensor with a maximum sensitivity of $19212.5 \mathrm{~nm} / \mathrm{RIU}$ (RI unit) in the RI range from 1.4304 to 1.4320 based on a tapered small core single mode fiber (SCSMF) structure [11]. In this work, we propose and demonstrate a highly sensitive ammonia sensor based on a sol-gel silica coated tapered SCSMF structure. The best measurement resolution of $16 \mathrm{ppb}$ is achieved for gas concentrations of $0.5 \mathrm{ppm}$ to $2.5 \mathrm{ppm}$.

\section{EXPERIMENTAL SETUP AND SENSOR FABRICATION}

In this experiment, a tapered SCSMF structure with a waist diameter of $13.5 \mu \mathrm{m}$ was fabricated by using a customized microheater brushing technique [12]. A silica sol solution for the coating layer was prepared as follows: 1) $10 \mathrm{ml}$ of hydrolyzing tetraethylorthosilicate (TEOS) was mixed with $5 \mathrm{ml}$ ethanol using magnetic stirring for $20 \mathrm{~min}$ at room temperature; 2) then $1 \mathrm{ml} 0.1$ $\mathrm{mol} / \mathrm{L} \mathrm{HCl}$ solution was added into the mixture followed with further stirring for $300 \mathrm{~min}$; 3) the resulting silica sol solution was sealed in a small bottle and stored in a refrigerator during the experimental trials. Each sensor sample was fabricated by applying a thin layer of silica on the tapered fiber surface by passing the tapered SCSMF section through a drop of the silica sol solution using a motor controlled translation stage. A single pass of the silica drop from one side of the fiber to the other 
side is defined as a one-pass coating. By repeating the one pass coating process, different silica coating thicknesses can be realized. After the coating process, the sensor was cured under ambient conditions for two weeks before the test.

(a)

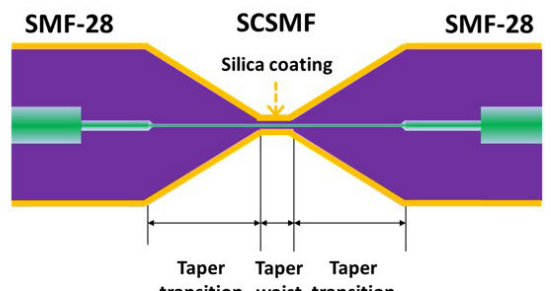

(b)

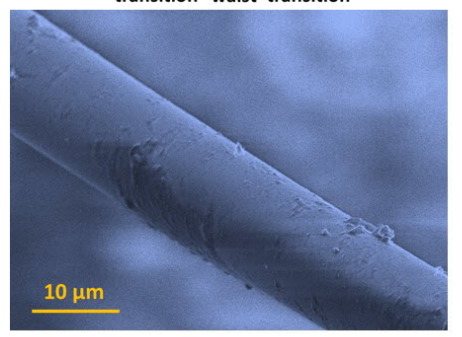

(c)

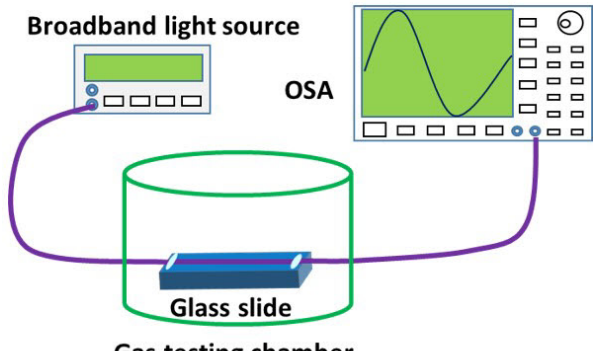

Gas testing chamber

Fig. 1. Schematic diagram of: (a) Tapered SCSMF structure; (b) SEM image of the taper waist section after coating process and (c) Experimental setup for ammonia gas sensing.

Figure 1(a) illustrates a schematic diagram of an 8-pass silica-coated ammonia sensor and Fig. 1(b) shows an SEM image of the taper waist section. It is clear that the silica coating is smooth at the taper waist section. A schematic diagram of the test system for ammonia gas sensing is shown in Fig. 1(c). Light from a broadband light source (Thorlabs S5FC1005S) is launched into the tapered SCSMF structure and the transmitted light is measured by an optical spectrum analyzer (OSA) (Agilent 86142B). A defined amount of diluted ammonia liquid was dropped in the gas testing chamber by a micro-syringe. The ammonia liquid evaporated naturally, resulting in an ammonia gas vapour. All the tests were conducted at room temperature.

\section{RESULTS AND DISCUSSION}

Figure 2(a) shows the measured spectral responses at different ammonia concentrations and Fig. 2(b) shows the dependency of the measured wavelength shift vs. ammonia concentration. As one can see from Fig. 2(a), as the ammonia gas concentration increases, the dip wavelength shifts to a longer wavelength monotonically. However the shift rate decreases as the ammonia concentration increases, which indicates that the sensor has a higher sensitivity as well as better resolution for lower ammonia concentrations. A linear fit has been performed for the measured wavelength shift from 0.5 ppm to $2.5 \mathrm{ppm}$ as shown in Fig 2(c). The measurement resolution is estimated as $16 \mathrm{ppb}$ assuming the OSA has a wavelength resolution of $0.01 \mathrm{~nm}$. Better resolution may be achieved for even lower ammonia concentrations.

It is worth pointing out that while reducing the tapered waist diameter of such a fiber sensor even further might result in a higher sensitivity, a tapered fiber with a smaller waist diameter is more fragile compared to that with a larger waist diameter, which could limit the sensor stability. A thicker coating may also improve the sensor sensitivity, as has been shown previously for other fiber sensors that involve coatings [13].
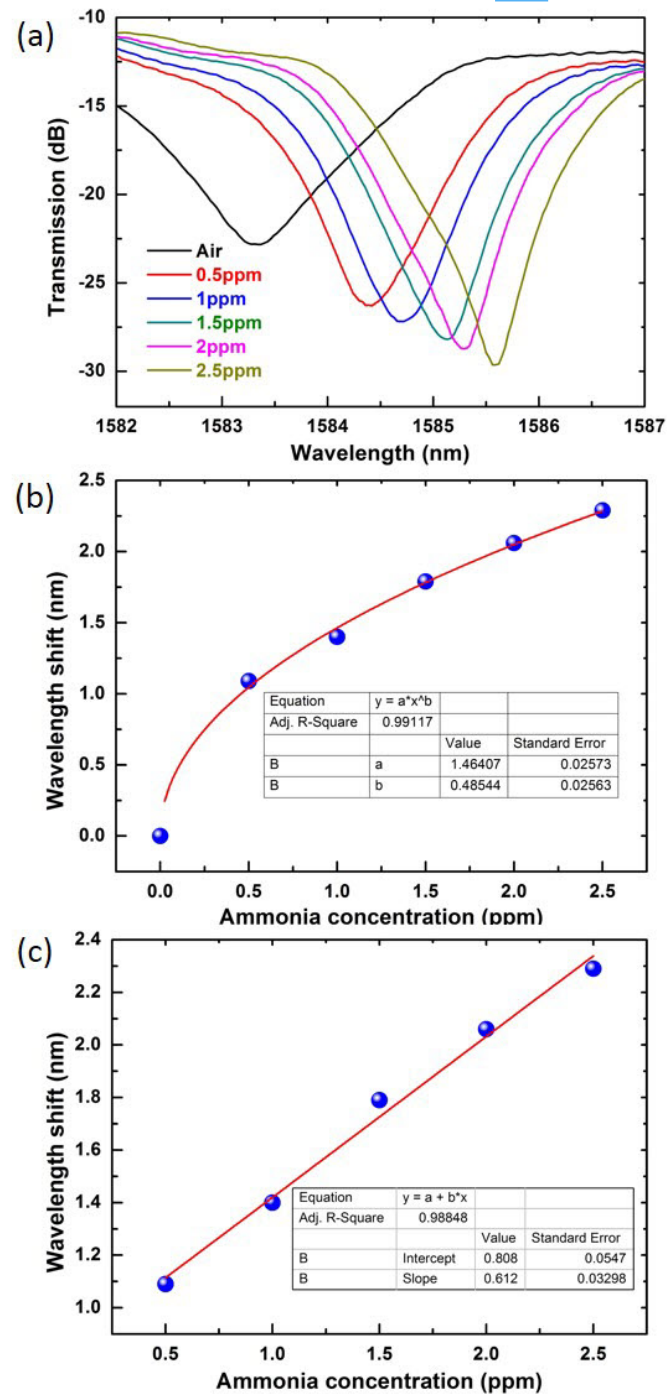

Fig. 2. (a) Normalized measured spectral response at different ammonia concentrations; (b) Measured spectral wavelength shift vs. ammonia concentration and measured data fitted with: (b) a nonlinear function and (c) a linear function with corresponding parameters listed in the inset tables. 
The response and recovery times are illustrated for a range of ammonia concentrations in Fig. 3. The response time is defined as the time that takes the sensor to reach $90 \%$ of its full response and the recovery time as the time to fall down to $10 \%$ of the full response. The sensor's response time is estimated to be less than 5 minutes, while the recovery time is estimated to be less than 10 minutes. It should be noted that in our experiment the ammonia evaporating process takes longer time than it should be, because the ammonia solution used in the experiment is highly diluted with water and the evaporation is not heat assisted. Due to these shortcomings of our setup, the actual response and recovery times to ammonia gas may well be even shorter. Besides, the actual sensor sensitivity should be also higher than we achieved from the experiment as ammonia does not fully evaporate from the water.

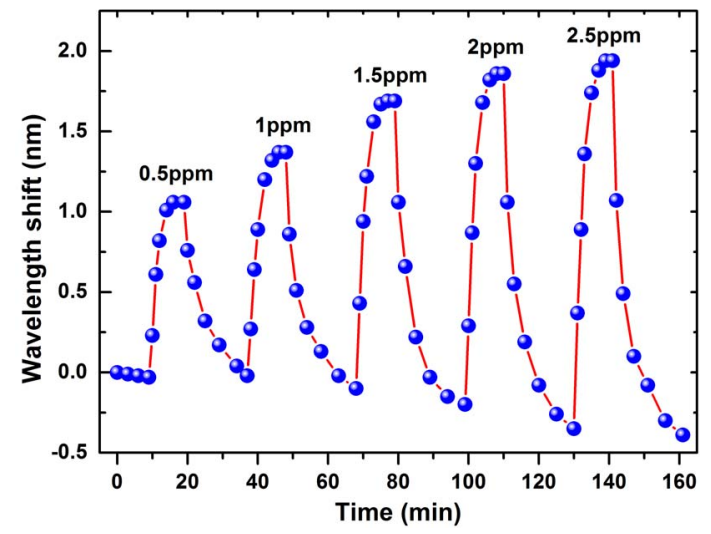

Fig. 3. Sensor's response and recovery at different ammonia concentrations.

\section{CONCLUSION}

In conclusion, a novel ammonia gas sensor is proposed and experimentally investigated based on a silica-coated tapered SCSMF fiber structure. A tapered SCSMF fiber structure with a taper waist diameter of $13.5 \mu \mathrm{m}$ was fabricated using the microheater brushing technique. Silica sol-gel was prepared and coated on the fiber surface as a sensing layer for detecting ammonia gas concentration. The experimental results show that the sensor offers ultra-high sensitivity to ammonia, the best resolution of the ammonia sensor is estimated to be as low as $16 \mathrm{ppb}$ from $0.5 \mathrm{ppm}$ to $2.5 \mathrm{ppm}$ while the response and recovery times are less than 5 and 10 minutes.

\section{ACKNOWLEDGMENTS}

This work was support by FIOSRAIGH 2012 (Dean of Graduate Students' Award); The Open Fund of IPOC (BUPT); Science Foundation Ireland (SFI/13/TIDA/B2707, SFI/13/ISCA/2845).

\section{REFERENCES}

[1] P. Warneck, Chemistry of the Natural Atmosphere, Academic Press Inc., 1998.

[2] S. Mukherjee, T. Sakorikar, A. Mukherjee, and Abha Misra, "Water-responsive carbon nanotubes for selective detection of toxic gases," Appl. Phys. Lett. 106(11), $113108(2015)$.

[3] A. L. Sharma, K. Kumar, and A. Deep, "Nanostructured polyaniline films on silicon for sensitive sensing of ammonia," Sens. Actuators A 198, 107-112 (2013).

[4] S. K. Sinha, "Growth and ammonia sensing properties of Zn1-xSnxO nanofibers," Sen. Actuators B 219, 192-198 (2015).

[5] J. Elham; M. Hadi, "Direct analysis of human breath ammonia using corona discharge ion mobility spectrometry," J. Pharmaceut biomed. 88, 315-320 (2014).

[6] A.Og. Dikovska, G.B. Atanasova, N.N. Nedyalkov, P.K. Stefanov, P.A. Atanasov, E.I. Karakoleva, and A.Ts. Andreev, "Optical sensing of ammonia using $\mathrm{ZnO}$ nanostructure grown on a side-polished optical-fiber," Sen. Actuators B 146(1), 331-336 (2010).

[7] S. K. Mishra, D. Kumari, and B. D. Gupta, "Surface plasmon resonance based fiber optic ammonia gas sensor using ITO and polyaniline," Sen. Actuators B 171-172, 976-983 (2012).

[8] S. A. Ibrahim, N. A. Rahman, M. H. Abu Bakar, S. H. Girei, M. H. Yaacob, H. Ahmad, and M. A. Mahdi, "Room temperature ammonia sensing using tapered multimode fiber coated with polyaniline nanofibers," Optics Express 23(3), 2837-2845 (2015).

[9] J. E. MAPES and R. P. EISCHENS, J. Phys. Chem. vol. 58(12), 1059-1062 (1954).

[10] G. A. Blomfield, and L. H. Little, "Chemisorption of ammonia on silica," Can. J. Chem. 51, 1771-1781 (1972).

[11] D. Liu, A. K. Mallik, J. Yuan, C. Yu, G. Farrell, Y. Semenova, and Q. Wu, "High sensitivity refractive index sensor based on a tapered small core single-mode fiber structure," Opt. Lett. 40(17) 4166-4169 (2015).

[12] G. Brambilla, V. Finazzi, and D. Richardson, "Ultra-low-loss optical fiber nanotapers," Opt. Exp. 12(10), 2258-2263 (2004).

[13] J. Mathew, Y. Semenova, and G. Farrell, "Effect of coating thickness on the sensitivity of a humidity sensor based on an Agarose coated photonic crystal fiber interferometer", Opt. Exp. 21(5), 6313-6320 (2012). 